\title{
Wu Cheng'en: Viaje al Oeste o Las aventuras del Rey mono, uno de los mayores clásicos de la literatura china ${ }^{1}$.
}

Por Oriol Caudevilla Parellada. Miembro del Grupo de Investigación ADS.

"It is said that in ancient times there was a magic rock on the Mountain of Flowers and Fruit of Aolai County in Tungsheng State. The rock had been favored the elements of nature for millions of years. Then, one day, suddenly, it burst open, giving birth to a stone egg from which a stone monkey emerged."

Éste es el inicio de la obra Viaje al Oeste, (西遊記, Jouney to the West, obra también conocida en inglés como Monkey y en ocasiones como The pilgrim Monkey), que es una de las cuatro grandes novelas de la literatura china. Fue publicada por primera vez en 1590, de forma anónima, aunque posteriormente se ha atribuido su autoría a Wu Cheng'en (吴承恩), poeta y novelista durante la dinastía Ming. Autores como Xianshen Zhou consideran que la publicó de forma anónima debido al hecho de que Viaje al Oeste fue escrita en lengua china vulgar, y no imitando el estilo más culto y clásico de las dinastías Han y Tang.

Considero de interés realizar un comentario sobre esta obra para la web no sólo por el gran interés literario de esta obra (que lo tiene), sino básicamente por su temática. En la obra, como posteriormente veremos, los animales comparten pleno protagonismo con los humanos. Es más, el verdadero protagonista de la obra es el Rey Mono, personaje que en China resulta de grana atractivo sobre todo para los niños, y que sin duda puede incentivar el amor hacia los animales por parte de muchos jóvenes. Además, como después remarcaré, en esta obra el humano no vive solo, sino que vive rodeado de animales, de dioses... estableciéndose entre ellos una perfecta simbiosis. Porque los humanos necesitamos a los animales, y esta necesidad queda perfectamente reflejada en esta obra.

\footnotetext{
${ }^{1}$ Las dos versiones que he cotejado para realizar este comentario han sido las siguientes:

*Wu Ch'eng-en, Monkey, trans. Arthur Waley, [1943] (New York: Grove Press, 1984) (versión abreviada).

*Viaje al Oeste. Las aventuras del Rey Mono. Colección Libros del Tiempo 178. Prólogo Jesús Ferrero, traducción directa del chino Enrique P. Gatón, Imelda Huang Wuang. Cartoné (Tercera edición). Madrid: Ediciones Siruela. (versión completa).
} 
En cualquier caso, dejando a un margen la autoría de la obra y la motivación del comentario, Viaje al Oeste es una de las más importantes obras de la literatura china (junto con Outlaws of the Marsh, Romance of the Three Kingdoms y Dream of the Red Chamber), hecho que provoca que las historias que en dicha obra se cuentan sean conocidas por muchísimos habitantes de China, y que sea una obra que forma parte del folklore, de la tradición popular china más conocida. En China encontramos muchas películas, muchos cuentos infantiles y muchas canciones que contienen referencias al rey mono, o al monje Tripitaka.

Quien busque realismo, en Viaje al Oeste no lo va a encontrar. Es una gran epopeya, siendo quizás su equivalente europeo la llíada o la Odisea homéricas, con muchos matices, claro está. Es una epopeya budista, en la cual los dioses, las transformaciones, los bodhisattvas ${ }^{2}$, la magia... gozan de gran importancia. Pero sin dejar de lado en ninguna ocasión el hecho de que esta historia pretende además ser una crítica a la burocracia, no sólo a la burocracia política, sino también a la burocracia religiosa.

La historia que se narra es aparentemente sencilla: el peregrinaje del monje Hiuan Tsang (conocido también como Tripitaka) de China a India con el fin de obtener las Escrituras Sagradas, el Gran Vehículo del Budismo. Esta misión le es encomendada a Tripitaka por la bodhisattva Kouan-Yin, quien a la vez cumple órdenes de Buda. Tripitaka no estará sólo en su camino, ya que será acompañado por el Rey Mono (probablemente el verdadero protagonista de la historia, cuyo nacimiento y vida antes del peregrinaje es detalladamente contada en la obra), y también por un dragón y por un puerco. En esta obra encontramos una mezcla única de belleza y de absurdidad, de profundidad. El folklore, la alegoría, la religión, la historia, la sátira contra la burocracia, la poesía...

La versión más conocida de esta obra en Occidente es la traducción que realizó el sinólogo Arthur Waley ${ }^{3}$. Esta versión está abreviada respecto de la original. La razón es que las obras clásicas de la literatura china, y ésta en especial, son extremadamente largas, y Waley consideró que lo mejor era reducir la obra de cien capítulos a los treinta más importantes. No

\footnotetext{
${ }^{2}$ Bodhisattva es una palabra en sánscrito que hace referencia a un ser iluminado que no ha entrado en el nirvāna, y que a cambio ha decidido permanecer en el mundo y salvar a los seres vivientes. Al cultivar nuestras cualidades inherentes como el amor y la compasión, podemos despertar lo que en sanscrito se llama " bodhi" o la gran mente, la fuente de todas las cualidades positivas, aquella que realza la efectividad y profundidad de nuestro trabajo siendo mucho más poderosa que nuestra mente común.

${ }^{3}$ Wu Ch'eng-en, Monkey, trans. Arthur Waley, [1943] (New York: Grove Press, 1984) (versión abreviada).
} 
obstante, recientemente también se han publicado versiones íntegras de la obra. ${ }^{4}$ Como establece Waley en el prólogo de su edición, el texto original es de una extensión extrema e incluso en los institutos chinos es habitual leer ediciones abreviadas. Lo más habitual es que las ediciones abreviadas chinas mantuvieran el mismo número de capítulos que la versión original (cien), reduciéndose cada capítulo. Waley, en cambio, optó por seleccionar los treinta capítulos que consideró más importantes, traduciéndolos, no obstante, íntegramente. SI me centro en Waley y su edición es para mostrar cómo llegó a Occidente esta obra, un clásico de la literatura china que durante muchos siglos resultó desconocida para el mundo occidental. De hecho, Waley se basó para realizar su traducción en la versión publicada en 1921 por la Oriental Press de Shanghai y que contaba con un prefacio del Dr. Hu Shih, embajador de China en Washington.

A continuación voy a resumir brevemente el argumento de la obra, teniendo en cuenta que resumir una epopeya de miles de páginas en unas pocas líneas es un ejercicio de ingratitud intelectual, puesto que implica eludir una gran cantidad de aspectos importantes de la obra. No obstante, mediante mi comentario sólo pretendo presentar la obra a un futuro lector, en ningún caso sustituir la lectura de este gran clásico.

El Rey Mono (o Sun Wukong) nació de una piedra. Quería ser como los inmortales, y liberarse de la muerte. Era muy inteligente y capaz, encontró un maestro taoísta que le enseñó muchos trucos de magia. Aprendió a realizar setenta y dos transformaciones: a transformarse en un árbol, en un pájaro, en un animal de rapiña, e incluso en un mosquito, para colarse en el vientre de un enemigo para luchar contra él de adentro hacia afuera. Utilizando las nubes como vehículo, podía llegar a viajar hasta 180.000 millas de golpe. Se autoproclamó rey, y además se autoproclamó "Gran Sabio Igual del Cielo", hecho que disgustó sobremanera al "Gran Emperador de Jade", la única autoridad en el cielo, los mares, la tierra y el mundo subterráneo. Ese acto de alta traición provocó el flagelo implacable de las huestes celestiales. Tras muchos enfrentamientos, un consejero celestial convenció al emperador para ofrecerle al mono un título oficial para apaciguarlo. El mono aceptó esta oferta en período de prueba. Se le ofreció el cargo de mozo de los Establos Celestiales. Sin embargo, se enteró a los pocos días de que fue engañado, y considerando el puesto de mozo de los establos como indigno para él, se rebeló, y volvió a la tierra para seguir ocupando el trono entre los monos.

\footnotetext{
${ }^{4}$ Viaje al Oeste. Las aventuras del Rey Mono. Colección Libros del Tiempo 178. Prólogo Jesús Ferrero, traducción directa del chino Enrique P. Gatón, Imelda Huang Wuang. Cartoné (Tercera edición). Madrid: Ediciones Siruela. (versión completa).
} 
Posteriormente, el ejército celestial logró someter al Rey Mono tras muchos combates. No obstante, todos los intentos posteriores de ejecutar al cautivo fracasaron. De hecho, el máximo daño que se le pudo infligir al mono fue provocar que sus ojos se volvieran rojos, tras hacer arder al mono durante horas. Además, estos ojos ardientes y rojos no sólo no le hacían daño al mono, sino que le permitían incluso ver lo que las personas normales no pueden ver.

Finalmente, el emperador de Jade solicitó ayuda a Buda. Éste ayudó a capturar al mono, encerrándolo en una gran montaña conocida como el Monte de los cinco dedos durante 500 años, hasta que el monje Tripitaka lo rescatará. El mono sobrevivió perfectamente esos 500 años a pesar del enorme peso y la presión de la montaña, aunque no se podía mover. Quinientos años más tarde, vino a su rescate el monje Tripitaka. Éste rescat al mono porque así se lo indica la bodhisattva Kouan-yin, que está interesada en que el peregrinaje del monje hacia la India sea triunfante. El Rey Mono escolta a Tripitaka, junto con otros dos discípulos (el puerco y el dragón acuático) con los que se encontrarán posteriormente . Allí, los cuatro comenzaron su viaje lleno de acción y aventuras.

El rey Mono, el monje Tripitaka, el Puerco y el Dragón se abren camino hacia el Paraíso Occidental y los sutras budistas. Altas montañas, profundos ríos caudalosos, y los demonios del mal están por venir. Pero el Mono es valiente e inteligente, e incluso aprende a comportarse correctamente.. Como pasan muchos años, aprenden a enfrentarse a los desafíos y a trabajar juntos. Cuando una tarea es demasiado difícil, la diosa Kouan-Yin les ayuda Después de viajar durante 14 años y 108.000 millas, el Mono y sus amigos llegan al Paraíso Occidental. Buda les da los sutras sagrados para que los lleven a China. Buda sabe que los viajeros han sufrido mucho en el viaje, y que también aprendieron algo nuevo sobre sí mismos. Buda les recompensa por su lealtad y trabajo duro con la vida inmortal y la felicidad.

Ahora que ya hemos resumido brevemente la obra, vamos a destacar algunos de sus elementos más esenciales. En primer lugar, resulta interesante centrarse en las alegorías, en el simbolismo presente en los personajes de la obra. Para hacerlo, analizaremos brevemente cada uno de los personajes de la obra: el Rey Mono simboliza la "mente", el ingenio, la inteligencia, el coraje, la perseverancia y la fuerza; Tripitaka, el monje, es un ser humano temeroso, preocupado por su propia supervivencia y la seguridad, al que le cuesta decidirse, es fácil de engañar y no ve a través de los disfraces de los demonios; el Puerco, es un ser ávido de placeres físicos, tales como dormir y comer; el Dragón acuático, es un ser servicial, paciente, además de ser muy fuerte y capaz de respirar bajo el agua y conserva algunas de sus habilidades mágicas de cuando trabajaba en el Cielo, como la capacidad de transformar una pequeña calabaza en una gigantesca, que puede ser utilizado para cruzar los ríos; el Emperador de Jade en el Cielo, aunque es gobernante del Cielo y la Tierra, no es tanto un Dios supremo como un administrador supremo (más adelante ya haré referencia a la sátira y crítica 
respecto a la burocracia presente en la obra). De hecho, es superado por los tres seres divinos del panteón chino, Buda, Lao Tse y Confucio, que se someten a fuerzas superiores, a una fuerza universal. El cielo chino sigue muy de cerca al gobierno de los emperadores chinos, como veremos (una burocracia, repleta de innumerables funcionarios con títulos pomposos, intentando fiscalizar cada actividad terrenal existente); Buda, es el título dado a Siddhartha Gautama, fundador del budismo, ahora venerado como un ser divino. Vivió en la India alrededor de 563 a 483 aC El título significa "El Iluminado" o "Iluminado". Como tal, se aplica a menudo por los budistas no sólo a Siddharta, sino a todos los que llegan a su estado de ánimo, un estado que se dice que trae una percepción de la verdadera naturaleza de la realidad y una liberación de la necesidad de nuevas vidas. Bodhisattva es un título relacionado para el que se ha iluminado, pero sigue en la tierra para ayudar a los demás hacia esa meta; Kwan Yin (Kuan Yin, o Guan Yin), esta bodhisattva, comúnmente llamada la Diosa de la Misericordia, es el favorito de ser divino de China. Su nombre significa "hacer caso a los gritos." Ella escucha y ayuda a todos aquellos que claman a los necesitados.

De todos los personajes, el más importante es, como antes he comentado, el Mono (en algunos momentos denominado Rey Mono, en otros Gran Simio Sabio, Gran Sabio Igual del Cielo...). Tal es su importancia que en la cultura popular asiática, que no sólo china, ha influido en gran cantidad de personajes: así, muchos autores (Waley entre ellos) establecen que el Rey Mono es el personaje más importante de la literatura asiática. En cualquier cosa, tanto si es el personaje más importante como si no lo es, es innegable su enorme influencia: por ejemplo, Durante el gobierno de Mao en China usó al Rey Mono (conocido en muchas ocasiones como Sun Wukong), como ejemplo de cómo deberían ser las personas. Mao frecuentemente hablaba sobre el buen ejemplo del Rey Mono, citando su "temeridad de pensamiento, trabajo, orientado al objetivo y rescatando a China de la pobreza" Y, centrándonos en ejemplos más populares, podríamos destacar que el archifamoso personaje de Son Goku (del manga y anime japonés Dragon Ball) se basa en Sun Wukong, el Rey Mono, porque Son Goku es la pronunciación japonesa del personaje original. O también la película The forbidden Kingdom , protagonizada por Jet Li y Jackie Chan, y que nos narra las aventuras de un joven americano que encuentra en un anticuario un bastón, precisamente el bastón que perteneció al Rey Mono, quien ahora se encuentra prisionero del Emperador de Jade. Éstos son sólo dos ejemplos de los centenares que podría haber encontrado acerca de la importancia del Rey Mono en el folklore asiático. En Hong Kong se conmemora en el templo budista de Sau Mau Ping, que tiene un relicario para Sun Wukong.

Y, se preguntará el lector, ¿̇por qué razón el Rey Mono resulta tan atractivo? Pues bien, la respuesta, que antes ya he apuntado, es muy simple: el Rey Mono es un personaje muy inteligente, extremadamente fuerte y también extremadamente travieso. Esta combinación produce que sea un personaje atractivo para todo tipo de lector. Así, Sun YOUJUN ${ }^{5}$ opina que:

\footnotetext{
${ }^{5}$ YOUJUN es un popular autor de cuentos para niños de la República Popular de China. Las citas que reproducimos son extraídas de El correo de la Unesco, junio de 1982.
} 
"Cuando era un niño, me gustaba proclamar orgullosamente: "iYo soy Sun Wukong". Ahora, sin habérselo enseñado, mi hijo de nueve años también declara: "iYo soy Sun Wukong!". Sería difícil encontrar a un niño chino que no se identifique con Sun Wukong, el Rey Mono. De este modo, los niños aman a este héroe tan maravilloso que nunca se someterá a la opresión ni a la ofensa. No importa cuán fuertes sean sus enemigos, él se atreverá a resistir y a vencerlos con sus habilidades. Por ejemplo, Cuando la corte del infierno decide que, de acuerdo con el "Libro de la Vida y la Muerte", el plazo de vida del mono Sun Wukong ha terminado, y arrastra su alma a las regiones del averno, el héroe saca su arma, el "bastón de las argollas de oro", de dentro de su oreja y conquista su camino hacia el Palacio del Rey del Infierno. Tachando su nombre y la fecha de su muerte del "Libro de la Vida y la Muerte", como también los de otros monos, declara: "iEsto lo deja establecido! iNo estamos bajo vuestro control!". A los niños les gusta el Mono Sun Wukong porque ven en él un reflejo de sí mismos y se identifican con él de muchas maneras. A Sun Wukong le place permitirse travesuras, enérgicamente y sin descanso, y siempre trata de superar las limitaciones."

Entonces, viendo cómo es el Rey Mono, podemos relacionar esta cuestión con el respeto hacia los animales. Si el lector puede amar tanto al Rey Mono, ¿sería capaz de dañar luego a un mono en la vida real? Mi respuesta es no. Si la infancia de un niño ha transcurrido adorando a este personaje, resulta complicado pensar que posteriormente pueda dañar voluntariamente a un mono y por extensión a cualquier otro animal.

Así, como considera Teresa GIMÉNEZ-CANDELA ${ }^{6}$, catedrática de Derecho Romano y Animal Law Professor: "El respeto por los animales es una actitud que se educa. Despertar la sensibilidad por los animales, por su bienestar, por el respeto de sus intereses, puede y debe fomentarse en todos los niveles de la población. El lenguaje y los medios que se empleen pueden diferir, pero lo que no puede diferir es la convicción de que con ello estamos contribuyendo a mejorar la convivencia entre los humanos y los animales y entre los humanos mismos, pues, en definitiva, una cultura de la convivencia es una cultura de la paz."

Uno de los aspectos que más me han llamado la atención de la obra es la fuerte crítica a la burocracia que en ella encontramos; en la obra encontramos una crítica hacia la burocracia celestial, pero, de hecho, debemos entender esta crítica extendida también a la burocracia terrestre. Y es que, como afirma Arthur Waley, " Los burócratas que aparecen en la obra son los Santos del Paraíso, y el lector se podría llegar a pensar que la sátira va dirigida más contra la religión que contra la administración. De hecho, es una idea admitida en China

\footnotetext{
${ }^{6}$ Teresa GIMÉNEZ-CANDELA, "Educar para la convivencia, educar para la paz". Front Row de dA web Center de octubre de 2010. Enlace: http://www.derechoanimal.info/esp/page/1442/educar-para-laconvivencia-educar-para-la-paz
} 
que la jerarquía celeste es una fiel réplica del gobierno sobre la tierra. Los otros pueblos sostenemos posiciones ambiguas, pero en la sociedad tradicional china este punto está totalmente claro: el cielo no es otra cosa que todo el sistema burocrático humano transportado en bloque".

La relación de esta obra con el mundo de los animales es clara; en el fondo, los animales son los verdaderos protagonistas de la obra, empezando por el Mono, el personaje principal de la obra, probablemente el personaje que a lo largo de la obra evoluciona más desde un plano psicológico, puesto que poco a poco va dejando a un lado sus travesuras y acciones poco meditadas, deviniendo cada vez más un personaje reflexivo, aunque sin perder en ningún momento su carisma , y sin dejar de despertar en ningún momento una sensación de simpatía a la mayoría de los lectores.

Como afirma Sánchez Zepeda ${ }^{7}, " E l$ ser humano no vive sólo en este planeta, todo lo contrario.

Todas las especies, animales y vegetales, tienen, al igual que el hombre, un lugar en este mundo en el que todos hemos sido creados, y por lo tanto, como el hombre, una razón de su existencia, una razón propia como ser vivo y una razón ajena como parte de este universo."

En esta obra observamos plenamente cómo se plasma esta afirmación que acabamos de reproducir: el hombre no vive solo, vive rodeado de animales, de dioses... que conviven en el mundo de forma simbiótica, necesitándose los unos a los otros. Quizás deberíamos aprender a veces a pensar de esta forma, y dejar de lado las concepciones antropocéntricas que solamente tiene en cuenta al ser humano como legítimo habitante de nuestro planeta, eludiendo el claro hecho de que nosotros, como humanos, necesitamos a los animales y a los vegetales, y viceversa.

En resumen, se trata de una obra cuya lectura resulta especialmente grata para todo tipo de lector, puesto que es un gran clásico de la literatura china del cual podemos aprender mucho y con el cual nos podemos divertir. Cierto es que el desconocimiento de algunos aspectos del budismo o de la cultura china puede hacer que algunos lectores quizás no aprecien la obra en su totalidad, pero en cualquier caso es una obra fácil de ser entendida en líneas generales.

\footnotetext{
${ }^{7}$ Rodolfo SÁNCHEZ ZEPEDA, "El maltrato a los animales: un problema que cuestiona nuestra propia racionalidad", publicado en dA webCenter en junio de 2011 (http://www.derechoanimal.info/images/pdf/Rodolfo_S_Zepeda_articulo_ii.pdf)
} 
El gran filósofo chino Lao Tse, fundador del Taoísmo (y que vimos que también aparecía en nuestra obra), sentenció que: "Quienes aceptan al mundo, es porque no se ocupan de él. Quienes se ocupan del mundo, no lo aceptan tal cual es. Un camino de mil pasos comienza en un solo paso".

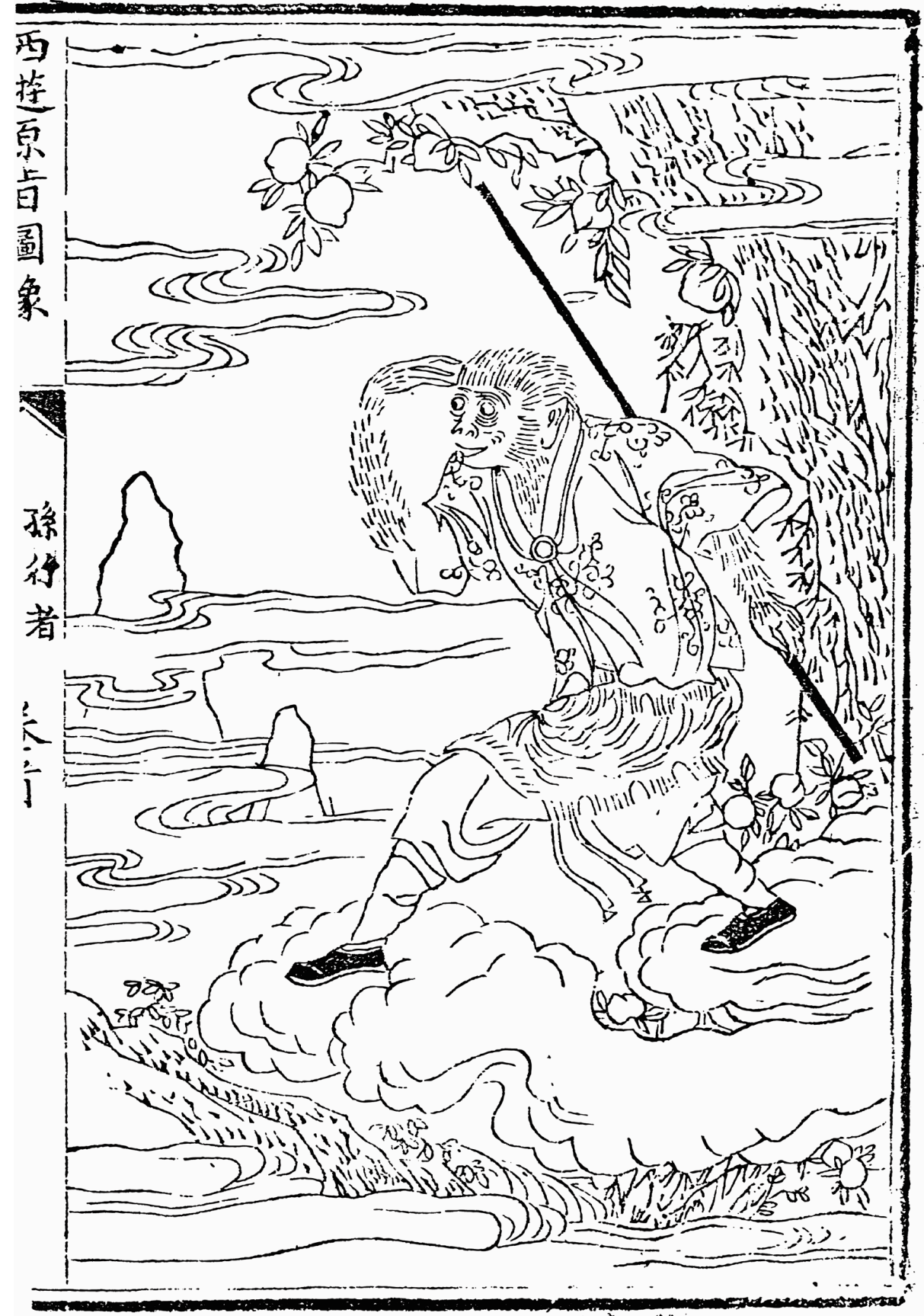

Sun Wukong (el Rey Mono).

Ilustración china del siglo XV. 